\title{
Rivastigmine but not vardenafil reverses cannabis- induced impairment of verbal memory in healthy humans
}

Citation for published version (APA):

Theunissen, E. L., Heckman, P., de Sousa Fernandes Perna, E. B., Kuypers, K. P. C., Sambeth, A., Blokland, A., Prickaerts, J., Toennes, S. W., \& Ramaekers, J. G. (2015). Rivastigmine but not vardenafil reverses cannabis-induced impairment of verbal memory in healthy humans. Psychopharmacology, 232(2), 343-353. https://doi.org/10.1007/s00213-014-3667-2

Document status and date:

Published: 01/01/2015

DOI:

10.1007/s00213-014-3667-2

Document Version:

Publisher's PDF, also known as Version of record

\section{Document license:}

Taverne

\section{Please check the document version of this publication:}

- A submitted manuscript is the version of the article upon submission and before peer-review. There can be important differences between the submitted version and the official published version of record.

People interested in the research are advised to contact the author for the final version of the publication, or visit the DOI to the publisher's website.

- The final author version and the galley proof are versions of the publication after peer review.

- The final published version features the final layout of the paper including the volume, issue and page numbers.

Link to publication

\footnotetext{
General rights rights.

- You may freely distribute the URL identifying the publication in the public portal. please follow below link for the End User Agreement:

www.umlib.nl/taverne-license

Take down policy

If you believe that this document breaches copyright please contact us at:

repository@maastrichtuniversity.nl

providing details and we will investigate your claim.
}

Copyright and moral rights for the publications made accessible in the public portal are retained by the authors and/or other copyright owners and it is a condition of accessing publications that users recognise and abide by the legal requirements associated with these

- Users may download and print one copy of any publication from the public portal for the purpose of private study or research.

- You may not further distribute the material or use it for any profit-making activity or commercial gain

If the publication is distributed under the terms of Article $25 \mathrm{fa}$ of the Dutch Copyright Act, indicated by the "Taverne" license above, 


\title{
Rivastigmine but not vardenafil reverses cannabis-induced impairment of verbal memory in healthy humans
}

\author{
E. L. Theunissen • P. Heckman • E. B. de Sousa \\ Fernandes Perna $\cdot$ K. P. C. Kuypers $\cdot$ A. Sambeth • \\ A. Blokland • J. Prickaerts $\cdot$ S. W. Toennes $\cdot$ \\ J. G. Ramaekers
}

Received: 15 April 2014 / Accepted: 16 June 2014 / Published online: 8 July 2014

(C) Springer-Verlag Berlin Heidelberg 2014

\begin{abstract}
Rationale One of the most often reported cognitive deficits of acute cannabis administration is an impaired recall of previously learned information.

Objective The aim of the present study was to determine whether cannabis-induced memory impairment in humans is mediated via glutamatergic or cholinergic pathways.

Methods Fifteen occasional cannabis users participated in a double-blind, placebo-controlled, six-way cross-over study. On separate test days, subjects received combinations of pretreatment (placebo, vardenafil $20 \mathrm{mg}$ or rivastigmine $3 \mathrm{mg}$ ) and treatment (placebo or 1,376 mg cannabis/kg body weight). Cognitive tests were administered immediately after inhalation of treatment was finished and included measures of memory (visual verbal learning task, prospective memory test, Sternberg memory test), perceptual-motor control (critical tracking task), attention (divided attention task) and motor impulsivity (stop signal task).

Results The results of this study demonstrate that subjects under the influence of cannabis were impaired in all memory tasks, in critical tracking, divided attention and the stop signal task. Pretreatment with rivastigmine attenuated the effect of cannabis on delayed recall and showed a trend towards
\end{abstract}

E. L. Theunissen $(\square) \cdot$ P. Heckman •

E. B. de Sousa Fernandes Perna $\cdot$ K. P. C. Kuypers · A. Sambeth •

A. Blokland · J. G. Ramaekers

Department of Neuropsychology and Psychopharmacology, Faculty

of Psychology and Neuroscience, Maastricht University,

P.O. Box 616, 6200, MD Maastricht, Netherlands

e-mail: e.theunissen@maastrichtuniversity.nl

J. Prickaerts

Department of Psychiatry and Psychology, School for Mental Health and Neuroscience, Maastricht University, Maastricht, Netherlands

S. W. Toennes

Department of Forensic Toxicology, Institute of Legal Medicine,

Goethe University of Frankfurt, Frankfurt, Germany significance on immediate recall. When cannabis was given in combination with vardenafil, there were no significant interaction effects in any of the tasks.

Conclusions The present data therefore suggest that acetylcholine plays an important role in cannabis-induced memory impairment, whereas similar results for glutamate have not been demonstrated in this study.

Keywords Memory $\cdot$ Cannabis $\cdot$ Glutamate $\cdot$ Acetylcholine

\section{Introduction}

The acute effects of cannabis on cognitive functions have been assessed in numerous experimental studies (Chait and Perry 1994; Curran et al. 2002; Hall and Solowij 1998; Ramaekers et al. 2009a). These studies have generally shown that delta-9tetrahydrocannabinol (THC, the principal psychoactive constituent of cannabis), in doses between 40 and $300 \mu \mathrm{g} / \mathrm{kg}$, causes a dose-dependent reduction in performance in laboratory tasks measuring memory, divided and sustained attention, reaction time, tracking, and motor function (Curran et al. 2002; Ramaekers et al. 2009a; Ranganathan and D'Souza 2006). Impaired learning and recall are among the most often reported cognitive deficits observed during cannabis intoxication. In particular, immediate recall, delayed recall and recognition of items learned while being under the influence of THC are impaired, whereas recall of items learned before cannabis administration is generally not affected while recalled in an intoxicated state. This suggests that THC specifically impairs acquisition and consolidation of information into memory, but not its retrieval from memory (Ameri 1999; Miller and Branconnier 1983).

Probable sites for the amnestic effect of cannabis are the hippocampus and the prefrontal cortex (Bhattacharyya et al. 2009; Bossong et al. 2012), structures which are highly 
involved in various forms of learning and memory. Large amounts of cannabinoid receptors (CB1) and anandamide, the endogenous cannabinoid, have been found in the hippocampus and the prefrontal cortex, suggesting a functional role of CB1 receptors in learning and memory (Davies et al. 2002; Egerton et al. 2006). Animal studies have also shown that CB1 receptors in these structures are particularly abundant on presynaptic cholinergic, GABA-ergic, and glutamatergic terminals (Davies et al. 2002; Lichtman et al. 2002).

The supposed physiological substrate of learning and memory is long-term potentiation (LTP), which involves changes in the connections between neurons. The NMDA glutamate receptor has long been known to be involved in LTP (Bliss and Collingridge 1993), and to be important for the acquisition and consolidation of information (Riedel et al. 2003). By binding at the presynaptic CB1 receptors, cannabinoids decrease the release of glutamate and disrupt LTP (Murray et al. 2007). However, to this date, the role of glutamate in cannabis-induced memory impairment in humans has not been determined. A classic approach to explore this relationship would be to reverse the THC-induced memory deficit by using glutamate agonists. However, such studies have never been conducted due to the neurotoxicity associated with these compounds. To circumvent this problem, glutamate concentrations could be indirectly increased with a non-toxic selective phosphodiesterase type 5 inhibitor (PDE5i). PDE5i's are presently marketed for erectile dysfunction, but there is substantial evidence that these drugs also promote memory acquisition and consolidation in animals (Devan et al. 2007; Reneerkens et al. 2012; Uthayathas et al. 2013). PDE5 breaks down the cyclic nucleotide cGMP (Bender and Beavo 2006), which presynaptically stimulates the release of glutamate (Neitz et al. 2011). Thus, selective PDE5i's increase central levels of cGMP (Prickaerts et al. 2002; Riazi et al. 2006), and consequently glutamate (Uthayathas et al. 2007, 2013), and may thereby reverse the effects of THC on glutamate.

Hippocampal acetycholine also plays a role in information acquisition and LTP (Hasselmo 2006). For instance, scopolamine, which blocks the muscarinic cholinergic receptors, has been shown to impair acquisition but not retrieval of information (Atri et al. 2004). In addition, cholinesterase inhibitors have been shown to reverse memory impairment in participants treated with scopolamine, and in Alzheimer's patients (Dawson and Iversen 1993; Ebmeier et al. 1992). Cannabinoids also act on the cholinergic system, and in fact, cannabisinduced memory impairments resemble those of cholinergic antagonists. By binding at the presynaptic $\mathrm{CB} 1$ receptors located at the cholinergic nerve terminals, cannabinoids inhibit acetylcholine release (Kathmann et al. 2001). However, until now, the hypothesis that cannabis-induced memory impairment is related to a decrement in acetylcholine release has been difficult to prove. Nava et al. (2000), for instance, showed that in rats, the decrease in extracellular hippocampal acetylcholine concentrations was delayed compared to the timing of the memory effect of THC (Nava et al. 2000). In addition, Lichtman and Martin (1996) were unable to show that a cholinesterase inhibitor (physostigmine) counteracted THC-induced memory impairment in rats (Lichtman and Martin 1996). However, eptastigmine, a more potent and long-lasting second-generation cholinesterase inhibitor, was able to reverse the memory deficit in rats (Braida and Sala 2000; Giacobini 2004; Lichtman et al. 2002). In humans, the hypothesis that cannabis-induced memory impairment is caused by a reduction in acetylcholine release and can be reversed by co-administration of a cholinesterase inhibitor has not yet been tested.

The aim of the present study was to determine whether cannabis-induced memory impairment in humans is mediated via glutamatergic or cholinergic pathways. The role of acetylcholine was investigated using the secondgeneration cholinesterase inhibitor rivastigmine. The clinically approved non-toxic selective PDE5i vardenafil was used to indirectly increase levels of glutamate. In addition to measures of memory impairment, some other cognitive tests were included, which have previously shown to be sensitive to the impairing effect of THC (Ramaekers et al. 2006, 2009a). These tests were included to demonstrate whether a possible interaction of rivastigmine or vardenafil with cannabis is specific to memory. As previous studies with rivastigmine and vardenafil have only been able to improve memory in memory-impaired subjects (Giacobini 2004; Pepeu and Giovannini 2010; Reneerkens et al. 2013b), we hypothesized that the memory-improving effects of rivastigmine and vardenafil would only be evident when our participants were under the influence of cannabis, but not when they were not intoxicated.

\section{Methods}

The study was approved by the standing Medical Ethics Committee of Maastricht University and was carried out in compliance with the current revision of the Declaration of Helsinki (amended in 2008, Seoul) and the International Conference on Harmonization guidelines for Good Clinical Practice. A permit for obtaining, storing, and administering cannabis was obtained from the Dutch drug enforcement administration. All subjects gave written informed consent and received financial compensation for their participation.

\section{Subjects}

A total of 21 occasional users of cannabis were recruited via advertisements placed around Maastricht University and in local coffee shops. Participants were screened using a health questionnaire and underwent a medical examination 
(including an electrocardiogram (ECG), haematology and blood chemistry, urinalysis, and drug and pregnancy screening). The following inclusion criteria applied to participants: occasional use of cannabis (minimal 1 year experience, with a minimum and maximum use of 8 and 36 times/year), free from psychotropic medication; good physical health, as determined by medical examination and laboratory analysis; absence of any major medical, endocrine and neurological conditions; body mass index (weight/length ${ }^{2}$ ) between 18 and $28 \mathrm{~kg} / \mathrm{m}^{2}$; and written informed consent. Exclusion criteria were as follows: history of drug abuse (excluding cannabis), as assessed by drug urine screens and questionnaires; excessive drinking ( $>20$ alcoholic consumptions/week); pregnancy or lactation or failure to use contraceptives; hypertension (diastolic $>100$; systolic $>170$ ); and history of psychiatric disorders.

\section{Design and treatments}

The study was conducted according to a double-blind, placebo-controlled, six-way cross-over design. Pretreatment consisted of placebo, vardenafil $20 \mathrm{mg}$ (VAR) or rivastigmine $3 \mathrm{mg}$ (RIV), which was administered orally in identical looking capsules. Doses of vardenafil $20 \mathrm{mg}$ and rivastigmine $3 \mathrm{mg}$ represent regular therapeutic doses, and both drugs reach a $T_{\max }$ of around $1 \mathrm{~h}$ (Bischoff 2004; Gottwald and Rozanski 1999). Treatment consisted of placebo or $1,376 \mathrm{mg}$ cannabis/ $\mathrm{kg}$ body weight $(150 \mu \mathrm{g}$ THC/kg body weight). On separate test days, the following combinations were given: placebo+ placebo, placebo+cannabis, VAR+placebo, VAR+cannabis, RIV+placebo, and RIV+cannabis.

Medicinal cannabis, type Bedrobinol, was provided by the Dutch Bureau for Medicinal Cannabis. Bedrobinol contained $11 \%$ THC and $<1 \%$ cannabidiol. Cannabis or placebo was heated using a Volcano vaporizer (Storz-Bickel, Tuttlingen, Germany). The vapour was trapped in a valve balloon. Subjects put the mouthpiece of the balloon to their lips and inhaled deeply, held their breath for $10 \mathrm{~s}$, and then exhaled. The volume of the balloon was inhaled in 7 to 10 subsequent breaths and emptied within 5 to $10 \mathrm{~min}$.

\section{Procedure}

Prior to the first test day, subjects were trained extensively in all cognitive tests, and in using the vaporizer, in order to familiarize them with all tests and minimize practice effects. Subjects were not allowed to use alcohol or caffeine on the test day or the day prior to testing. Smoking was prohibited for $30 \mathrm{~min}$ prior and during test days. Subjects were asked to arrive at the site well rested. On each test day, subjects were instructed to have a standard breakfast before coming to the site, and no other food was allowed until the end of the test day. Subjects were instructed to continue their cannabis use as normal but were requested to abstain from cannabis from about 5 days prior to the test day, to make sure they were negative on the test day. Drug and alcohol tests were performed upon arrival, using an alcohol breath test and urine drug screen (assessing the presence of morphine, cocaine, cannabis, methamphetamine and amphetamine). For those with a negative alcohol and drug screen, pretreatment was administered, and 45 min later, the inhalation procedure started. The cognitive tests began within 10 min after finishing the inhalation procedure and were administered in two parts. Part one included visual verbal learning, critical tracking, prospective memory and stop signal tasks. Part two consisted of the Sternberg memory and divided attention task. In between the two parts, subjects had a break, in which they stayed at the site and could watch TV, read, or use the internet. Four blood samples were taken during the test day: immediately, $1,1.5$ and $2 \mathrm{~h}$ after cannabis/placebo inhalation was finished. See Table 1 for an overview of the test day. Test days always started at the same time in the morning and were separated by a minimum wash-out period of 7 days to avoid cross-condition contamination.

\section{Performance tests}

Visual verbal learning task (VVLT) The VVLT is a modified version of the Rey Auditory Verbal Learning Test (Rey 1964), validated by (Klaassen et al. 2002) and used in many studies since (e.g. Linssen et al. 2014). Thirty Dutch mono-syllabic meaningful nouns and adjectives were presented one by one on a computer screen. The words in the lists had been matched for abstraction. Six different lists were used for the different test days.

Subjects had to verbally recall as many words as possible (immediate recall) at the end of the list presentation. This procedure was repeated three times; immediate recall scores

Table 1 Overview of the test day

\begin{tabular}{ll}
\hline Time (h) & Activity \\
\hline Arrival & Drug and alcohol screens \\
-45 min & Pretreatment \\
0 & Cannabis administration \\
10 min-1 hr 5 min & Blood sample 1 \\
& Test battery 1 (VVLT-immediate recall, CTT, \\
& PMT, SST, VVLT-delayed recall) \\
& Blood sample 2 \\
$1 \mathrm{hr} \mathrm{5} \mathrm{min-1} \mathrm{hr} \mathrm{30} \mathrm{min}$ & Break \\
$1 \mathrm{hr} 30 \mathrm{~min}-2 \mathrm{hr} 10 \mathrm{~min}$ & Blood sample 3 \\
& Test battery 2 (SMT, DAT) \\
& Blood sample 4 \\
$3 \mathrm{hr} \mathrm{50} \mathrm{min}$ & End test day \\
\hline
\end{tabular}

VVLT visual verbal learning task, CTT critical tracking task, $P M T$ prospective memory task, SST stop signal task, SMT Sternberg memory task, $D A T$ divided attention task 
were summed to comprise the total immediate recall score. After a 30-min delay, subjects were asked to recall as many of the previously learnt words as possible (delayed recall). Hereafter, subjects were given a delayed recognition task containing 15 new words and 15 words from the previously shown list. The subjects' task was to indicate as fast as possible whether the presented word was a new one, or one from the original list.

Dependent variables were the total immediate recall score, the delayed recall score, the delayed recognition score and reaction time (RT) for recognition.

Prospective memory task (PMT) The PMT was developed to examine prospective memory performance (Ramaekers et al. 2009b). The subjects were shown the letter A or B in the middle of a computer screen. Subjects were required to respond to each letter as quickly as possible by pressing one of two response buttons (go trials). Letters were displayed for $3 \mathrm{~s}$ and the interval before displaying the following letter was $0.5 \mathrm{~s}$. The test consisted of 240 trials, in which each of the two letters was presented equally often. A counter in the left corner of the screen continuously indicated the trial number. A prospective memory signal which consisted of a visual cue, i.e. a future trial number, appeared at random in the right corner of the screen for $1 \mathrm{~s}$ in 30 trials during the test. These signals indicated that subjects were required to withhold any response during this future trial number (nogo trial). Prospective memory trials were always the 5th, 10th or 15th trial (i.e. memory delays of 30,60 and 90 s) following the onset of the prospective memory signal. The memory set did not exceed three prospective signals at a time. Dependent variables were RT on go trials and the proportion of inhibited responses on prospective memory trials (no-go trials).

Sternberg memory task (SMT) The SMT measures speed and efficiency of working memory (Sternberg 1966). The task consisted of three blocks; in each block, a memory set was presented which subjects had to remember. The number of items in the memory set increased during the task; in the first block, the memory set comprised one letter, in the second block, two letters, and in the third block, four letters. Subsequently, subjects were shown 90 letters one by one in the middle of the computer screen, and each letter was presented for maximally $2 \mathrm{~s}$. In half of the trials, a letter from the memory set was presented, while the other half consisted of other letters. After each letter, the participant had to indicate as quickly as possible whether the presented letter belonged to the memory set or not, by using one of two response buttons. Different target letters were used in the different memory sets and on different test days. Dependent performance variables were RT and accuracy (correctly remembered letters) for each individual block.
Stop signal task (SST) The SST measures motor impulsivity, which is defined as the inability to inhibit an activated or precued response, leading to errors of commission. The current test is adapted from an earlier version used by Fillmore et al. (2002) and has been validated for showing stimulant and sedative drug effects (Ramaekers and Kuypers 2006). The task required subjects to make quick responses to visual go signals and to inhibit their response if a subsequent visual stop signal, i.e. '*', appeared in one of the four corners of the screen. The go signals were four letters (A, B, C, D) presented one at a time in the centre of the computer screen. Letters were displayed for $500 \mathrm{~ms}$ and a 1.5 -s inter-stimulus interval was used before the next letter was displayed. The test consisted of 176 trials in which each of the four letter stimuli were presented equally often. Stop signals were presented 12 times at each of the four delays after the onset of a letter: 50, 150, 250 and $350 \mathrm{~ms}$. Dependent variables were go reaction time, stop reaction time, response accuracy, omission (not responding on go trials) and commission errors (not inhibiting a no-go trial). Stop reaction time represents the estimated mean time required to inhibit a response. Stop reaction time is calculated by subtracting the stop signal delay from the RT on go trials associated with $n$th percentile of the RT distribution (Logan 1994).

Critical tracking task (CTT) The CTT measures the subject's ability to control a displayed error signal in a first-order compensatory tracking task (Jex et al. 1966). Error is displayed as a horizontal deviation of a cursor from the midpoint on a horizontal, linear scale. Compensatory joystick movements null the error by returning the cursor to the midpoint. The subject's compensatory response increases in frequency with an increasing phase lag. Control is lost at the point at which the compensatory response lags the cursor's last movement by $180^{\circ}$. The response frequency at this point is defined as the critical frequency, or lambda. The test included five trials of which the lowest and the highest scores were removed. The average of the remaining scores was taken as the final lambda-c score.

Divided attention task (DAT) The DAT measures the ability to divide attention between two tasks performed simultaneously (Moskowitz 1973). The primary task consists of the tracking task described above. The difficulty of the primary task is set at a constant level of $50 \%$ of the subjects' maximum capacity, as determined in the training session. Tracking error is measured as the difference in millimetre between the average position of the cursor and the middle of the horizontal scale. As a secondary task, the subject monitors 24 single digits in the corners of the computer screen. These numbers change asynchronously and subjects have to react to the target number ' 2 ' by removing their foot as fast as possible from a pedal switch. In total, 75 targets and 375 non-targets were presented. 
Mean absolute tracking error (in millimetres) and number of control losses were the performance measures of the primary task. Number of correct detections and average RT (in milliseconds) were the dependent variables of the secondary task.

\section{Subjective high}

Using 100-mm visual analogue scales (VAS), subjects were asked to indicate how 'high' they were feeling, with 0 indicating 'not high at all' and 100 indicating 'extremely high'. Subjects were asked to indicate this at baseline, immediately after cannabis, and at $1,1.5$ and $2 \mathrm{~h}$ after cannabis.

\section{Pharmacokinetics}

Blood samples $(8 \mathrm{ml})$ were taken immediately and $1,1.5$ and $2 \mathrm{~h}$ hours after cannabis/placebo inhalation. Blood samples were centrifuged and serum was frozen at $-20^{\circ} \mathrm{C}$ until analyses for pharmacokinetic assessments. Cannabinoid concentrations (THC with its metabolites $\mathrm{OH}-\mathrm{THC}$ and THC$\mathrm{COOH}$ ) were determined using a validated and accredited routine method for the analysis of cannabinoids in forensic blood samples. The procedure essentially consists of an automated solid-phase extraction and gas chromatography with mass spectrometric detection with a limit of quantification of $1 \mathrm{ng} / \mathrm{ml}$ which has also been successfully used in previous studies (Toennes et al. 2008).

Vardenafil and rivastigmine were determined in serum after liquid-liquid extraction and analysis using liquid chromatography-tandem mass spectrometry with very low limits of quantification, covering the range of therapeutic concentrations $(0.2-200 \mathrm{ng} / \mathrm{ml}$ for vardenafil and $0.02-$ $100 \mathrm{ng} / \mathrm{ml}$ for rivastigmine). Analyses were performed by the Institute of Legal Medicine, Goethe University of Frankfurt (Germany).

\section{Statistics}

The hypotheses that pretreatment with vardenafil or rivastigmine would prevent cannabis-induced memory impairment was tested in two separate general linear model (GLM) repeated measures ANOVA analyses. Effects of cannabis, vardenafil and their interaction were analysed by GLM 1 with vardenafil (two levels: present and absent) and cannabis (two levels: present and absent) as the main factors. Effects of cannabis, rivastigmine, and their interaction were analysed by means of GLM 2 with rivastigmine (two levels: present and absent) and cannabis (two levels: present and absent) as the main factors. The alpha criterion significance level was set at $p=0.05$. When a significant interaction effect was found, additional drug contrasts with sequential Bonferroni correction were performed. Pharmacokinetic results were analysed with a repeated measures ANOVA, with condition (two levels, var/riv+placebo and var/riv+cannabis, or three levels, pla + cannabis, var+cannabis, and riv+cannabis) and time (four levels: samples 1-4) as a factor. In case of a violation of the sphericity assumption, Greenhouse-Geisser estimates of sphericity was used to correct the degrees of freedom. All statistical tests were conducted using SPSS version 15.0.

\section{Results}

Six subjects quitted the study prematurely, due to matters unrelated to the study (four subjects were not able to combine participation with their work or study, and two participants did not comply with the study restrictions). Therefore, data from 15 subjects (nine males and six females) entered statistical analysis (see Table 2 for a summary of the participant's demographics and drug use characteristics).

An overview of mean scores of all tests is given in Table 3 . Tables 4 and 5 provide overviews of $p$ and $F$ values of the statistical tests.

Side effects

Six subjects reported feeling nauseated or dizzy in the RIV+ cannabis condition. On one occasion, this occurred shortly after administration of pretreatment, and on four other occasions, this occurred within $15 \mathrm{~min}$ after treatment. On one

Table 2 Subject demographics (mean, SD) and drug use characteristics $(N=15)$

\begin{tabular}{lll}
\hline Variable & Mean (SD) & \\
Age (years) & $21.23(1.76)$ & \\
Weight (kg) & $67.33(8.75)$ & \\
Cannabis use (times)/ & $19.1(17.76)$ & \\
$\quad$ year & & \\
Joints per occasion & $1.43(1.1)$ & \\
Years of cannabis use & $4.1(1.8)$ & \\
Alcohol drinks a week & $11.6(6.8)$ & \\
No. of regular tobacco & 5 & \\
users & & \\
& Mean frequency of use & No. of subject having \\
& \multicolumn{1}{c}{ (SD) } & used \\
XTC & $5.88(9.8)$ & 1 \\
Amphetamine & 4 & 3 \\
Cocaine & $11.67(11.6)$ & 6 \\
Mushrooms & $2.33(1.4)$ & 1 \\
Salvia & 1 & 1 \\
Psychoactive truffles & 3 & \\
\hline
\end{tabular}


Table 3 Mean scores $( \pm \mathrm{SE})$ on subjective measures and cognitive tasks per drug treatment

\begin{tabular}{|c|c|c|c|c|c|c|}
\hline & $\mathrm{PLA}+\mathrm{PLA}$ & $\mathrm{VAR}+\mathrm{PLA}$ & RIV+PLA & $\mathrm{PLA}+\mathrm{CAN}$ & $\mathrm{VAR}+\mathrm{CAN}$ & $\mathrm{RIV}+\mathrm{CAN}$ \\
\hline Subjective high baseline (mm) & $3.2 \pm 1.4$ & $4.8 \pm 3.4$ & $2.3 \pm 1.1$ & $1.8 \pm 0.9$ & $2.0 \pm 1.4$ & $1.9 \pm 0.9$ \\
\hline Subjective high $0 \mathrm{~min}$ & $9.2 \pm 4.1$ & $8.2 \pm 3.5$ & $11.6 \pm 3.7$ & $73.2 \pm 4.1$ & $75.3 \pm 5.2$ & $69.1 \pm 6.5$ \\
\hline Subjective high $60 \mathrm{~min}$ & $8.1 \pm 4.1$ & $6.5 \pm 2.7$ & $12.1 \pm 5.6$ & $65.9 \pm 5.6$ & $67.2 \pm 4.3$ & $69.0 \pm 3.7$ \\
\hline Subjective high $90 \mathrm{~min}$. & $5.8 \pm 3.0$ & $4.9 \pm 2.3$ & $9.3 \pm 4.3$ & $55.1 \pm 6.2$ & $51.1 \pm 5.5$ & $55.7 \pm 6.2$ \\
\hline Subjective high $120 \mathrm{~min}$ & $3.9 \pm 2.2$ & $3.5 \pm 1.6$ & $3.7 \pm 2.0$ & $34.6 \pm 6.8$ & $33.3 \pm 5.8$ & $31.7 \pm 5.1$ \\
\hline VVLT immediate recall (no) & $44.93 \pm 3.25$ & $45.47 \pm 3.54$ & $43.87 \pm 3.15$ & $32.67 \pm 2.97$ & $36.20 \pm 3.23$ & $37.60 \pm 3.01$ \\
\hline VVLT delayed recall (no) & $15.00 \pm 1.52$ & $15.20 \pm 1.54$ & $14.07 \pm 1.59$ & $10.47 \pm 1.07$ & $12.13 \pm 1.48$ & $12.47 \pm 1.42$ \\
\hline VVLT RT recognition (ms) & $739.19 \pm 28.21$ & $717.90 \pm 61.03$ & $788.15 \pm 33.13$ & $813.59 \pm 43.21$ & $875.44 \pm 43.37$ & $696.35 \pm 81.77$ \\
\hline VVLT recognition (no) & $26.47 \pm 0.78$ & $25.67 \pm 2.22$ & $25.73 \pm 1.00$ & $25.50 \pm 0.40$ & $23.67 \pm 1.30$ & $20.40 \pm 2.53$ \\
\hline PMT RT (ms) & $729.81 \pm 52.35$ & $732.98 \pm 56.40$ & $744.88 \pm 43.81$ & $797.62 \pm 76.70$ & $820.92 \pm 54.82$ & $785.25 \pm 62.63$ \\
\hline PMT inhibited responses (no) & $25.13 \pm 1.68$ & $22.20 \pm 1.88$ & $24.00 \pm 1.90$ & $18.64 \pm 1.65$ & $16.33 \pm 1.98$ & $16.53 \pm 2.14$ \\
\hline SMT RT block 1 (ms) & $431.10 \pm 20.91$ & $434.08 \pm 18.48$ & $418.19 \pm 22.52$ & $435.78 \pm 40.88$ & $497.00 \pm 24.12$ & $446.62 \pm 42.06$ \\
\hline SMT RT block 2 (ms) & $464.11 \pm 20.51$ & $477.63 \pm 23.36$ & $459.57 \pm 22.03$ & $477.68 \pm 42.68$ & $513.48 \pm 18.19$ & $472.02 \pm 41.65$ \\
\hline SMT RT block 3 (ms) & $520.23 \pm 23.87$ & $530.020 \pm 19.95$ & $524.02 \pm 23.37$ & $550.23 \pm 53.30$ & $590.49 \pm 26.67$ & $526.79 \pm 45.71$ \\
\hline SMT accuracy block 1 (no) & $87.33 \pm 0.50$ & $86.80 \pm 0.60$ & $81.73 \pm 5.79$ & $76.33 \pm 7.57$ & $86.47 \pm 0.87$ & $80.87 \pm 5.80$ \\
\hline SMT accuracy block 2 (no) & $86.80 \pm 0.72$ & $86.33 \pm 0.65$ & $81.87 \pm 5.67$ & $74.47 \pm 7.01$ & $85.53 \pm 0.61$ & $78.40 \pm 5.83$ \\
\hline SMT accuracy block 4 (no) & $86.47 \pm 0.79$ & $86.33 \pm 0.77$ & $80.53 \pm 5.56$ & $73.67 \pm 6.74$ & $84.87 \pm 1.20$ & $78.20 \pm 5.80$ \\
\hline SST stop RT (ms) & $299.60 \pm 15.39$ & $301.07 \pm 19.68$ & $293.47 \pm 18.04$ & $324.71 \pm 22.95$ & $350.67 \pm 27.79$ & $336.80 \pm 29.65$ \\
\hline SST go RT (ms) & $617.96 \pm 34.08$ & $617 . \pm 38.85$ & $635.52 \pm 44.70$ & $653.49 \pm 47.61$ & $707.43 \pm 49.08$ & $655.96 \pm 53.36$ \\
\hline SST commission errors (no) & $14.27 \pm 3.35$ & $15.20 \pm 2.76$ & $12.87 \pm 2.75$ & $16.13 \pm 3.75$ & $16.13 \pm 2.69$ & $17.40 \pm 3.87$ \\
\hline SST omission errors (no) & $1.20 \pm 0.50$ & $1.53 \pm 0.84$ & $0.73 \pm 0.37$ & $1.43 \pm 0.50$ & $8.07 \pm 4.57$ & $2.53 \pm 0.74$ \\
\hline SST response accuracy (no) & $118.87 \pm 2.49$ & $121.47 \pm 1.26$ & $119.67 \pm 1.34$ & $115.00 \pm 2.29$ & $106.13 \pm 5.99$ & $112.73 \pm 3.83$ \\
\hline CTT lambda $(\mathrm{rad} / \mathrm{s})$ & $3.36 \pm 0.12$ & $3.38 \pm 0.12$ & $3.30 \pm 0.11$ & $2.81 \pm 0.14$ & $2.87 \pm 0.16$ & $3.01 \pm 0.18$ \\
\hline DAT correct detections (no) & $44.27 \pm 1.19$ & $40.13 \pm 3.13$ & $44.80 \pm 0.70$ & $40.67 \pm 1.46$ & $41.93 \pm 1.29$ & $38.00 \pm 3.32$ \\
\hline DAT control losses (no) & $14.60 \pm 5.36$ & $11.20 \pm 2.92$ & $8.87 \pm 2.15$ & $23.67 \pm 4.84$ & $27.07 \pm 8.73$ & $20.80 \pm 5.77$ \\
\hline DAT tracking error $(\mathrm{mm})$ & $19.62 \pm 0.85$ & $19.22 \pm 1.57$ & $18.40 \pm 1.00$ & $22.26 \pm 0.52$ & $20.99 \pm 0.65$ & $19.60 \pm 1.50$ \\
\hline DAT RT (ms) & $2062.1 \pm 81$ & $1864.2 \pm 155$ & $1968.3 \pm 64$ & $1979.6 \pm 54$ & $2124.1 \pm 85$ & $1907.1 \pm 156$ \\
\hline
\end{tabular}

$P L A$ placebo, $V A R$ vardenafil, $R I V$ rivastigmine, $C A N$ cannabis, $V V L T$ visual verbal learning task, $P M T$ prospective memory task, $C T T$ critical tracking task, $S S T$ stop signal task, $S M T$ Sternberg memory task, $D A T$ divided attention task, $R T$ reaction time

occasion, it was reported more than $1 \mathrm{~h}$ after treatment. As a result of these side effects, three subjects had to lie down for a couple of minutes before resuming with the tests, and one subject decided to stop any further testing that day (see missing data).

\section{Missing data}

One subject was unable to continue testing in the RIV+cannabis condition, resulting in missing data for DAT, SMT, VVLT delayed recall and recognition. Due to technical malfunctioning, computer responses were not registered for one person in the cannabis condition (resulting in missing data for SMT, VVLT recognition, PMT and SST). In addition, computer malfunctioning caused missing data for the DAT in the vardenafil condition for one person, VVLT recognition in the vardenafil condition for a second person, and VVLT recognition in the RIV+cannabis condition for a third person.
Subjective high

Both GLM's showed a significant effect of cannabis on the subjective high VAS measured immediately and at 1, 1.5 and $2 \mathrm{~h}$ after cannabis.

Visual verbal learning task

The interaction between rivastigmine and cannabis was significant for delayed recall and showed a tendency towards significance for immediate recall. There was no interaction between vardenafil and cannabis on any of the VVLT measures.

Cannabis significantly decreased immediate recall and increased recognition reaction time in both the vardenafil and rivastigmine comparisons. The delayed recall and recognition scores showed a significant impairing effect of cannabis in the vardenafil GLM comparison, while the effect on these 
Table 4 Summary of the results of the GLM1 analyses, with factors vardenafil (present-absent) and cannabis (present-absent)

\begin{tabular}{|c|c|c|c|c|c|c|c|c|c|c|}
\hline & \multicolumn{3}{|l|}{ VAR } & \multicolumn{3}{|l|}{ CAN } & \multicolumn{4}{|c|}{$\mathrm{VAR} \times \mathrm{CAN}$} \\
\hline & $p$ & $F$ & $\eta^{2}$ & $p$ & $F$ & $\eta^{2}$ & $p$ & $F$ & $\eta^{2}$ & $\mathrm{df}$ \\
\hline Subjective high baseline & ns & 0.21 & .015 & ns & 1.44 & .093 & ns & 0.16 & .011 & 1.14 \\
\hline Subjective high $0 \mathrm{~min}$ & ns & 0.07 & .005 & $<.001$ & 114.43 & .891 & ns & 0.32 & .023 & 1.14 \\
\hline Subjective high $60 \mathrm{~min}$ & ns & 0.00 & .000 & $<.001$ & 116.82 & .893 & ns & 0.21 & .015 & 1.14 \\
\hline Subjective high $90 \mathrm{~min}$ & ns & 0.40 & .028 & $<.001$ & 76.88 & .846 & ns & 0.19 & .013 & 1.14 \\
\hline Subjective high $120 \mathrm{~min}$ & ns & 0.03 & .002 & $<.001$ & 34.26 & .710 & ns & 0.01 & .001 & 1.14 \\
\hline VVLT immediate recall & ns & 1.66 & .106 & .002 & 13.76 & .496 & ns & 0.87 & .058 & 1.14 \\
\hline VVLT delayed recall & ns & 1.38 & .090 & .012 & 8.29 & .372 & ns & 2.11 & .131 & 1.14 \\
\hline VVLT RT recognition & ns & 4.80 & .286 & .001 & 18.40 & .605 & ns & 0.46 & .037 & 1.12 \\
\hline VVLT recognition & ns & 0.15 & .012 & .014 & 8.33 & .410 & ns & 2.44 & .169 & 1.12 \\
\hline PMT RT & ns & 0.09 & .007 & .007 & 10.03 & .435 & ns & 0.26 & .020 & 1.13 \\
\hline PMT inhibited responses & .035 & 5.55 & .299 & .000 & 27.17 & .676 & ns & 0.12 & .009 & 1.13 \\
\hline SMT RT block 1 & ns & 1.44 & .100 & .003 & 12.78 & .496 & ns & 2.74 & .174 & 1.13 \\
\hline SMT RT block 2 & ns & 0.04 & .035 & .014 & 8.15 & .385 & ns & 0.25 & .019 & 1.13 \\
\hline SMT RT block 3 & ns & 0.05 & .004 & .001 & 17.78 & .578 & ns & 0.00 & .000 & 1.13 \\
\hline SST omission errors & ns & 0.16 & .012 & ns & 0.66 & .049 & ns & 0.00 & .000 & 1.13 \\
\hline SST go RT & ns & 0.39 & .029 & .03 & 5.96 & .314 & ns & 0.58 & .043 & 1.13 \\
\hline SST response accuracy & ns & 3.99 & .134 & .007 & 10.17 & .439 & ns & 3.99 & .235 & 1.13 \\
\hline CTT lambda ${ }_{c}$ & ns & .263 & .018 & $<.001$ & 21.87 & .610 & ns & .09 & .006 & 1.14 \\
\hline DAT correct detections & ns & .028 & .002 & .008 & 9.99 & .435 & ns & 1.64 & .112 & 1.13 \\
\hline DAT tracking error & ns & 1.15 & .081 & .059 & 4.28 & .248 & ns & 3.61 & .217 & 1.13 \\
\hline DAT RT & ns & 0.14 & .010 & ns & 0.14 & .018 & .026 & 6.36 & .328 & 1.13 \\
\hline
\end{tabular}

$V A R$ vardenafil, $C A N$ cannabis, $\eta^{2}$ partial eta-squared values, $d f$ degrees of freedom, $V V L T$ visual verbal learning task, $P M T$ prospective memory task, $C T T$ critical tracking task, SST stop signal task, SMT Sternberg memory task, DAT divided attention task, $R T$ reaction time, $n s$ non-significant. Significant effects are marked in bold; trends towards significance are marked in italics

variables showed a tendency towards significance in the other. Vardenafil did not affect any measures of the VVLT.

Contrast analysis showed that compared to cannabis, RIV+ cannabis significantly increased immediate recall score $\left(F_{1,14}=8.77 ; p<.012\right)$ and delayed recall score $\left(F_{1,13}=15.47\right.$, $p<.01)$. Cannabis decreased delayed recall score compared to placebo $\left(F_{1,13}=11.55, p<.012\right)$, and both cannabis and RIV+ cannabis decreased immediate recall compared to placebo $\left(F_{1,14}=14.29, p<.01 ; \mathrm{F}_{1,14}=7.62, p<.016\right)$. Rivastigmine did not differ significantly from placebo or RIV+cannabis. Mean (SE) immediate and delayed recall scores are presented in Fig. 1.

\section{Prospective memory task}

There were no significant interactions between vardenafil or rivastimine and THC.

The number of correctly inhibited memory trials was significantly decreased by cannabis in both the vardenafil and rivastigmine comparisons, and by vardenafil. Reaction time was significantly increased by cannabis in the vardenafil comparison.

\section{Sternberg memory test}

The Sternberg memory test was analysed with an extra factor workload (memory set; three levels). No significant interactions between vardenafil or rivastigmine and cannabis were found on any of the variables of the SMT.

Both GLM analyses showed that reaction time was significantly increased by cannabis $\left(F_{1,13}=18.21, \mathrm{p}=.001\right.$ and $\left.F_{1,12}=10.48, p<.01\right)$ and by workload $\left(F_{2,26}=43.37, p<.001\right.$ and $\left.F_{2,24}=36.99, p<.001\right)$. No interaction was found between cannabis and workload.

Stop signal task

No interactions between cannabis and vardenafil or rivastimine were found.

The accuracy on go trials was negatively affected by cannabis in both the vardenafil and rivastigmine comparisons. Cannabis 
Table 5 Summary of the results of the GLM2 analyses, with factors rivastigmine (present-absent) and cannabis (present-absent)

\begin{tabular}{|c|c|c|c|c|c|c|c|c|c|c|}
\hline & \multicolumn{3}{|l|}{ RIV } & \multicolumn{3}{|l|}{ CAN } & \multicolumn{4}{|c|}{$\mathrm{RIV} \times \mathrm{CAN}$} \\
\hline & $p$ & $F$ & $\eta^{2}$ & $p$ & $F$ & $\eta^{2}$ & $p$ & $F$ & $\eta^{2}$ & $\mathrm{df}$ \\
\hline Subjective high baseline & ns & 0.42 & .029 & ns & 0.92 & .062 & ns & 0.86 & .058 & 1.14 \\
\hline Subjective high $0 \mathrm{~min}$ & ns & 0.07 & .005 & $<.001$ & 77.81 & .848 & ns & 1.50 & .097 & 1.14 \\
\hline Subjective high $60 \mathrm{~min}$ & ns & 0.81 & .055 & $<.001$ & 113.33 & .890 & ns & 0.02 & .001 & 1.14 \\
\hline Subjective high $90 \mathrm{~min}$ & ns & 0.39 & .027 & $<.001$ & 64.57 & .822 & ns & 0,15 & .011 & 1.14 \\
\hline Subjective high $120 \mathrm{~min}$ & ns & 0.29 & .022 & $<.001$ & 35.81 & .734 & $\mathrm{~ns}$ & 0.29 & .022 & 1.14 \\
\hline VVLT immediate recall & ns & 2.87 & .170 & .003 & 13.28 & .487 & .063 & 4.10 & .226 & 1.14 \\
\hline VVLT delayed recall & ns & 2.35 & .153 & .08 & 3.60 & .217 & .002 & 14.61 & .529 & 1.13 \\
\hline VVLT RT recognition & ns & 1.78 & .139 & .007 & 11.14 & .503 & ns & 1.65 & .131 & 1.11 \\
\hline VVLT recognition & ns & 1.79 & .140 & .061 & 4.37 & .284 & ns & 1.27 & .104 & 1.11 \\
\hline PMT RT & ns & 0.02 & .002 & ns & 3.06 & .190 & ns & 0.62 & .046 & 1.13 \\
\hline PMT inhibited responses & ns & 3.46 & .210 & $<.001$ & 23.72 & .646 & ns & 0.44 & .033 & 1.13 \\
\hline SMT RT block 1 & ns & 0,07 & .006 & .011 & 9.14 & .432 & ns & 1.62 & .119 & 1.12 \\
\hline SMT RT block 2 & ns & 0.26 & .022 & .035 & 5.62 & .319 & ns & 0.02 & .002 & 1.12 \\
\hline SMT RT block 3 & ns & 0.65 & .051 & .004 & 12.68 & .514 & ns & 0.52 & .041 & 1.12 \\
\hline SST omission errors & ns & 1.36 & .095 & .03 & 5.97 & .315 & ns & 2.90 & .183 & 1.13 \\
\hline SST go RT & ns & 0.00 & .000 & ns & 1.33 & .093 & ns & 0.73 & .053 & 1.13 \\
\hline SST response accuracy & ns & 1.02 & .073 & .012 & 8.47 & .394 & ns & 1.04 & .074 & 1.13 \\
\hline CTT Lambda & ns & 0.78 & .053 & .001 & 16.12 & .535 & $\mathrm{~ns}$ & 2.62 & .158 & 1.14 \\
\hline DAT correct detections & ns & 0.02 & .001 & .002 & 15.91 & .550 & ns & 0.05 & .004 & 1.13 \\
\hline DAT tracking error & .004 & 12.30 & .486 & .006 & 10.78 & .453 & ns & 0.02 & .002 & 1.13 \\
\hline DAT RT & ns & 0.03 & .002 & ns & 0.00 & .000 & ns & 2.30 & .150 & 1.13 \\
\hline
\end{tabular}

$R I V$ rivastigmine, $C A N$ cannabis, $\eta^{2}$ partial eta-squared values, $d f$ degrees of freedom, $V V L T$ visual verbal learning task, PMT prospective memory task, $C T T$ critical tracking task, SST stop signal task, SMT Sternberg memory task, DAT divided attention task, $R T$ reaction time, $n s$ non-significant. Significant effects are marked in bold; trends towards significance are marked in italics

also increased reaction time in the vardenafil comparison and the number of omission errors in the rivastigmine comparison.

\section{Critical tracking task and divided attention task}

An interaction between vardenafil and cannabis was found on the reaction time of the DAT. However, contrast analyses showed no significant differences with cannabis or placebo. No interactions between cannabis and rivastigmine were found for the CTT or DAT scores.

A significant effect of cannabis on CTT score was found in both vardenafil and rivastigmine comparisons, with cannabis decreasing CTT scores. In the DAT, cannabis almost significantly increased tracking error in the vardenafil comparison, and this effect reached significance in the rivastigmine comparison. Also, rivastigmine significantly decreased tracking error. The number of correct detections was also significantly decreased by cannabis in both comparisons.
Pharmacokinetics

For two subjects, blood samples for all conditions are missing; three subjects are each missing two samples; and, for one subject, there is one sample missing. Repeated measures analyses demonstrated that there was no significant effect of condition or time on concentration of vardenafil or rivastigmine. For THC concentrations, a significant effect of time was demonstrated $\left(F_{1.01,12,09}=19.52, p=.001\right)$, but there was no significant effect between cannabis conditions. Mean (standard error (SE)) concentrations of THC and its metabolites in the three cannabis conditions are shown in Table 6.

\section{Discussion and conclusions}

The current study investigated the role of cholinergic and glutamatergic mechanisms involved in cannabisinduced memory impairment. Subjects were first given vardenafil or rivastigmine, followed by a single dose of cannabis or placebo. Subsequently, performance was 

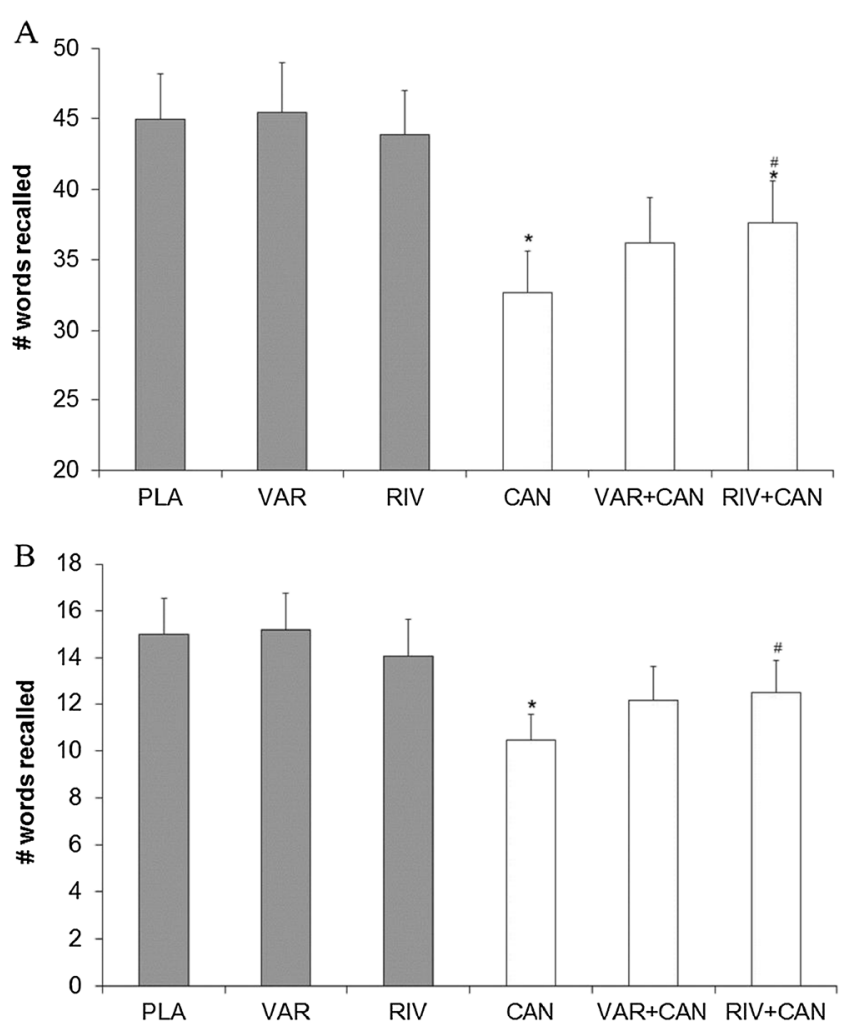

Fig. 1 Mean (SE) immediate (a) and delayed (b) recall score on the VVLT for each treatment condition. Asterisk indicates a significant difference from placebo (with sequential bonferroni correction); the number sign indicates a significant difference from THC (with sequential bonferroni correction); VAR vardenafil, $R I V$ rivastigmine, $C A N$ cannabis

measured on several memory tasks as well as on tasks tapping into other cognitive domains, in order to demonstrate specificity of the possible effects.

The results of this study demonstrate that subjects under the influence of cannabis were impaired in all memory tasks (Sternberg, VVLT and prospective memory). Specifically, cannabis increased reaction time in the Sternberg memory task and the VVLT recognition task, decreased immediate and delayed recall and recognition in the VVLT and the number of correct response inhibitions in the prospective memory task. In addition, cannabis also negatively affected performance in the critical tracking and divided attention tasks and in the stop signal task. These results are in accordance with previous studies demonstrating the impairing effects of cannabis on these tasks (Ramaekers et al. 2006, 2009a). In addition, the present results once more indicate that the impairing effects of cannabis on cognitive functions are found up until $2 \mathrm{~h}$ after administration of the drug; i.e. cannabis impaired performance on tests that were taken immediately after consuming cannabis, as well as tests that were taken 1.5 to $2 \mathrm{~h}$ later.

Pretreatment with rivastigmine showed a significant interaction with cannabis in the visual verbal memory task. When cannabis was given in combination with rivastigmine, delayed recall was less impaired. Separate drug-placebo contrasts confirmed that delayed recall after the rivastigmine + cannabis combination was significantly better compared to cannabis but was not significantly different from placebo. For immediate recall, the interaction effect between cannabis and rivastigmine showed a tendency towards an effect, with the combination of rivastigmine and cannabis apparently causing less impaired immediate recall than cannabis alone. When cannabis was given in combination with vardenafil, there were no significant interactions in any of the tasks.

In this study, we used the PDE5 inhibitor vardenafil, in an attempt to indirectly increase glutamate levels in the brain and to reverse the cannabis-induced memory impairment. Several studies with PDE5i's have previously demonstrated improved acquisition and consolidation in learning and memory tests, using predominantly rodents (Devan et al. 2007; Reneerkens et al. 2012). In humans, however, research on the cognitive effects of PDE5 inhibitors is scarce. One study investigating chronic dosing of the PDE5i udenafil showed improved executive function and performance on the mini-mental state examination in patients with erectile problems (Shim et al. 2011). However, studies using acute administration of vardenafil (Reneerkens et al. 2013b) or sildenafil (Schultheiss et al. 2001) have generally failed to show memory improving effects in healthy subjects. A possible explanation for this discrepancy between

Table 6 Mean (SD) concentrations of THC and its metabolites in serum (ng/ml) in the four samples taken during the day, for the three conditions in which THC was administered

\begin{tabular}{|c|c|c|c|c|c|c|c|c|c|}
\hline \multirow[t]{2}{*}{ Sample } & \multicolumn{4}{|l|}{ Cannabis } & \multicolumn{2}{|c|}{$\mathrm{VAR}+$ cannabis } & \multicolumn{3}{|c|}{ RIV+cannabis } \\
\hline & THC & OH-THC & THC-COOH & THC & OH-THC & THC-COOH & THC & OH-THC & THC-COOH \\
\hline 1 & $30.7(27.4)$ & $3.3(2.0)$ & $17.2(12.5)$ & $22.8(25.8)$ & $4.9(5.6)$ & $19.5(20.9)$ & $30.5(21.2)$ & $3.4(1.8)$ & $14.1(9.8)$ \\
\hline 2 & $6.3(3.9)$ & $2.2(1.2)$ & $17.3(11.1)$ & $4.2(2.4)$ & $1.9(1.1)$ & $17.9(19.9)$ & $4.5(2.1)$ & $1.9(1.0)$ & $15.4(7.9)$ \\
\hline 3 & $4.3(3.0)$ & $1.9(1.1)$ & $17.6(11.2)$ & $3.3(2.1)$ & $1.8(1.1)$ & $18.0(20.2)$ & $3.2(1.3)$ & $1.5(0.9)$ & $16.2(7.4)$ \\
\hline 4 & $2.5(1.7)$ & $1.3(0.7)$ & $14.7(10.7)$ & $2.1(1.2)$ & $1.4(0.9)$ & $16.4(18.1)$ & $1.9(0.9)$ & $1.3(0.6)$ & $13.8(6.9)$ \\
\hline
\end{tabular}

VAR vardenafil, $R I V$ rivastigmine, $O H$-THC 11-hydroxy- $\Delta^{9}$-THC, THC-COOH 11-nor-9-carboxy-THC 
animal and human effects of PDE5i's could be found in the translation in memory tests from animal to human studies. However, these tests are well established tests for studying human memory and should be sensitive enough to pick up any effects. Furthermore, the 20-mg dose of vardenafil used is comparable to effective doses in animals (Reneerkens et al. 2013a). In previous studies with healthy non-impaired humans, a ceiling effect might also have attenuated any improved cognition/ memory performance. In the current study, we therefore hypothesized to demonstrate that cannabis-induced impairment of memory could be reversed by PDE5i's. Our results, however, show that acute treatment with vardenafil is also unable to improve cannabis-induced memory impairment in humans. This does not necessarily mean that glutamate is not involved in the cannabisinduced memory impairment, but rather that memoryimproving effects of PDE5i's are difficult to demonstrate in humans.

Cholinesterase inhibitors, on the other hand, were previously found to be able to improve memory in impaired humans (Giacobini 2004; Pepeu and Giovannini 2010). In this study, memory-improving effects of rivastigmine alone were not demonstrated. This is most likely due to the fact that these were normal, young, healthy participants, who did not demonstrate memory impairments when not intoxicated. Cholinesterase inhibitors have also previously been demonstrated to reverse the cannabis-induced working memory impairment in rats (Braida and Sala 2000). Moreover, in the present study, we found some interaction of cannabis with rivastigmine, although this was only found for delayed recall of visually presented material. The other memory and cognitive tests did not show this interaction effect of cannabis and rivastigmine. In combination with previous results in rats, this is a strong indication that the acetylcholine system is, at least partly, involved in memory impairments seen after cannabis use. This is also in accordance with studies showing a reduced choline uptake in the hypothalamus and an inhibited synthesis of acetylcholine in rats after THC administration (Lindamood and Colasanti 1980). Some subjects experienced side effects when receiving the combination of rivastigmine and cannabis. These side effects may have caused subjects to perform below their maximal capacity. However, as all (except one) subjects were able to continue with the cognitive tests, we feel that these side effects had only minimal, if any, impact on the study results.

In conclusion, the present data suggest that acetylcholine plays an important role in cannabis-induced verbal memory impairment, whereas no experimental evidence was found for an involvement of glutamate.

\section{References}

Ameri A (1999) The effects of cannabinoids on the brain. Prog Neurobiol $58: 315-348$

Atri A, Sherman S, Norman KA, Kirchhoff BA, Nicolas MM, Greicius MD, Cramer SC, Breiter HC, Hasselmo ME, Stern CE (2004) Blockade of central cholinergic receptors impairs new learning and increases proactive interference in a word paired-associate memory task. Behav Neurosci 118:223

Bender AT, Beavo JA (2006) Cyclic nucleotide phosphodiesterases: molecular regulation to clinical use. Pharmacol Rev 58:488-520

Bhattacharyya S, Fusar-Poli P, Borgwardt S, Martin-Santos R, Nosarti C, O'Carroll C, Allen P, Seal ML, Fletcher PC, Crippa JA (2009) Modulation of mediotemporal and ventrostriatal function in humans by $\Delta 9$-tetrahydrocannabinol: a neural basis for the effects of Cannabis sativa on learning and psychosis. Arch Gen Psychiatry $66: 442-451$

Bischoff E (2004) Vardenafil preclinical trial data: potency, pharmacodynamics, pharmacokinetics, and adverse events. Int J Impot Res 16: S34-S37

Bliss TVP, Collingridge GL (1993) A synaptic model of memory: longterm potentiation in the hippocampus. Nature 361:31-39

Bossong MG, Jansma JM, van Hell HH, Jager G, Oudman E, Saliasi E, Kahn RS, Ramsey NF (2012) Effects of $\delta 9$-tetrahydrocannabinol on human working memory function. Biol Psychiatry 71:693-699

Braida D, Sala M (2000) Cannabinoid-induced working memory impairment is reversed by a second generation cholinesterase inhibitor in rats. Neuroreport 11:2025-2029

Chait LD, Perry JL (1994) Acute and residual effects of alcohol and marijuana, alone and in combination, on mood and performance. Psychopharmacology (Berl) 115:340-349

Curran HV, Brignell C, Fletcher S, Middleton P, Henry J (2002) Cognitive and subjective dose-response effects of acute oral Delta 9-tetrahydrocannabinol (THC) in infrequent cannabis users. Psychopharmacology (Berl) 164:61-70

Davies S, Pertwee R, Riedel G (2002) Functions of cannabinoid receptors in the hippocampus. Neuropharmacology 42:993-1007

Dawson GR, Iversen SD (1993) The effects of novel cholinesterase inhibitors and selective muscarinic receptor agonists in tests of reference and working memory. Behav Brain Res 57:143-153

Devan BD, Pistell PJ, Daffin LW Jr, Nelson CM, Duffy KB, Bowker JL, Bharati IS, Sierra-Mercado D, Spangler EL, Ingram DK (2007) Sildenafil citrate attenuates a complex maze impairment induced by intracerebroventricular infusion of the NOS inhibitor N $\omega$-nitroL-arginine methyl ester. Eur J Pharmacol 563:134-140

Ebmeier K, Hunter R, Curran S, Dougal N, Murray C, Wyper D, Patterson J, Hanson M, Siegfried K, Goodwin G (1992) Effects of a single dose of the acetylcholinesterase inhibitor velnacrine on recognition memory and regional cerebral blood flow in Alzheimer's disease. Psychopharmacology (Berl) 108:103-109

Egerton A, Allison C, Brett RR, Pratt JA (2006) Cannabinoids and prefrontal cortical function: insights from preclinical studies. Neurosci Biobehav Rev 30:680-695

Fillmore MT, Rush CR, Hays L (2002) Acute effects of oral cocaine on inhibitory control of behavior in humans. Drug Alcohol Depend 67: $157-167$

Giacobini E (2004) Cholinesterase inhibitors: new roles and therapeutic alternatives. Pharmacol Res 50:433-440

Gottwald MD, Rozanski RI (1999) Rivastigmine, a brain-region selective acetylcholinesterase inhibitor for treating Alzheimer's disease: review and current status. Expert Opin Investig Drugs 8:1673-1682

Hall W, Solowij N (1998) Adverse effects of cannabis. Lancet 352:16111616

Hasselmo ME (2006) The role of acetylcholine in learning and memory. Curr Opin Neurobiol 16:710-715 
Jex HR, McDonnell JD, Phatak AV (1966) A "critical" tracking task for man-machine research related to the operator's effective delay time. I. Theory and experiments with a first- order divergent controlled element. NASA CR-616. NASA Contract Rep NASA CR: 1-105.

Kathmann M, Weber B, Schlicker E (2001) Cannabinoid CB 1 receptormediated inhibition of acetylcholine release in the brain of NMRI, CD-1 and C57BL/6 J mice. Naunyn Schmiedeberg's Arch Pharmacol 363:50-56

Klaassen T, Riedel W, Deutz N, Van Praag H (2002) Mood congruent memory bias induced by tryptophan depletion. Psychol Med 32: $167-172$

Lichtman AH, Martin BR (1996) $\Delta^{9}$-Tetrahydrocannabinol impairs spatial memory through a cannabinoid receptor mechanism. Psychopharmacology (Berl) 126:125-131

Lichtman A, Varvel S, Martin B (2002) Endocannabinoids in cognition and dependence. Prostaglandins Leukot Essent Fat Acids 66:269285

Lindamood C, Colasanti BK (1980) Effects of delta 9tetrahydrocannabinol and cannabidiol on sodium-dependent high affinity choline uptake in the rat hippocampus. J Pharmacol Exp Ther 213:216-221

Linssen A, Sambeth A, Vuurman E, Riedel W (2014) Cognitive effects of methylphenidate and levodopa in healthy volunteers. Eur Neuropsychopharmacol 24:200-206

Logan GD (1994) On the ability to inhibit thought and action. In: Dagenbach D, Carr TH (eds) Inhibitory processes in attention, memory and language. Academic Press, San Diego, pp 189-239

Miller LL, Branconnier RJ (1983) Cannabis: Effects on memory and the cholinergic limbic system. Psychol Bull 93:441

Moskowitz H (1973) Laboratory studies of the effects of alcohol on some variables related to driving. J Saf Res 5:185-192

Murray RM, Morrison PD, Henquet C, Di Forti M (2007) Cannabis, the mind and society: the hash realities. Nat Rev Neurosci 8:885-895

Nava F, Carta G, Battasi A, Gessa G (2000) D2 dopamine receptors enable $\Delta^{9}$-tetrahydrocannabinol induced memory impairment and reduction of hippocampal extracellular acetylcholine concentration. Br J Pharmacol 130:1201-1210

Neitz A, Mergia E, Eysel UT, Koesling D, Mittmann T (2011) Presynaptic nitric oxide/cGMP facilitates glutamate release via hyperpolarization-activated cyclic nucleotide-gated channels in the hippocampus. Eur J Neurosci 33:1611-1621

Pepeu G, Giovannini MG (2010) Cholinesterase inhibitors and memory. Chem Biol Interact 187:403-408

Prickaerts J, Van Staveren W, Șik A, Markerink-van Ittersum M, Niewöhner U, Van der Staay F, Blokland A, De Vente J (2002) Effects of two selective phosphodiesterase type 5 inhibitors, sildenafil and vardenafil, on object recognition memory and hippocampal cyclic GMP levels in the rat. Neuroscience 113:351-361

Ramaekers JG, Kuypers KPC (2006) Acute effects of 3,4methylenedioxymethamphetamine (MDMA) on behavioral measures of impulsivity: alone and in combination with alcohol. Neuropsychopharmacology 31:1048-1055

Ramaekers JG, Kauert G, van Ruitenbeek P, Theunissen EL, Schneider E, Moeller MR (2006) High-Potency Marijuana Impairs Executive
Function and Inhibitory Motor Control. Neuropsychopharmacology 31:2296-2303

Ramaekers JG, Kauert G, Theunissen EL, Toennes SW, Moeller MR (2009a) Neurocognitive performance during acute THC intoxication in heavy and occasional cannabis users. J Psychopharmacol 23:266-277

Ramaekers JG, Kuypers KP, Wingen M, Heinecke A, Formisano E (2009b) Involvement of inferior parietal lobules in prospective memory impairment during acute MDMA (ecstasy) intoxication: an event-related fMRI study. Neuropsychopharmacology 34:1641-1648

Ranganathan M, D'Souza DC (2006) The acute effects of cannabinoids on memory in humans: a review. Psychopharmacology (Berl) 188 : 425-444

Reneerkens OA, Rutten K, Akkerman S, Blokland A, Shaffer CL, Menniti FS, Steinbusch HW, Prickaerts J (2012) Phosphodiesterase type 5 (PDE5) inhibition improves object recognition memory: indications for central and peripheral mechanisms. Neurobiol Learn Mem 97:370-379

Reneerkens O, Sambeth A, Ramaekers J, Steinbusch H, Blokland A, Prickaerts J (2013a) The effects of the phosphodiesterase type 5 inhibitor vardenafil on cognitive performance in healthy adults: a behavioralelectroencephalography study. J Psychopharmacol 27:600-608

Reneerkens O, Sambeth A, Van Duinen M, Blokland A, Steinbusch H, Prickaerts J (2013b) The PDE5 inhibitor vardenafil does not affect auditory sensory gating in rats and humans. Psychopharmacology (Berl) 225:303-312

Rey A (1964) L'examen Clinique en Psychologie. Presses Universitaires de France, Paris

Riazi K, Roshanpour M, Rafiei-Tabatabaei N, Homayoun H, Ebrahimi F, Dehpour AR (2006) The proconvulsant effect of sildenafil in mice: role of nitric oxide-cGMP pathway. Br J Pharmacol 147:935-943

Riedel G, Platt B, Micheau J (2003) Glutamate receptor function in learning and memory. Behav Brain Res 140:1-47

Schultheiss D, Müller S, Nager W, Stief C, Schlote N, Jonas U, Asvestis C, Johannes S, Münte T (2001) Central effects of sildenafil (Viagra) on auditory selective attention and verbal recognition memory in humans: a study with event-related brain potentials. World J Urol 19:46-50

Shim Y, Pae C, Kim S, Kim H, Kim J, Koh J (2011) Effects of repeated dosing with Udenafil (Zydena) on cognition, somatization and erection in patients with erectile dysfunction: a pilot study. Int J Impot Res 23:109-114

Sternberg S (1966) High-speed scanning in human memory. Science 153: 652-654

Toennes SW, Ramaekers JG, Theunissen EL, Moeller MR, Kauert GF (2008) Comparison of cannabinoid pharmacokinetic properties in occasional and heavy users smoking a marijuana or placebo joint. J Anal Toxicol 32:470-477

Uthayathas S, Karuppagounder SS, Thrash BM, Parameshwaran K, Suppiramaniam V, Dhanasekaran M (2007) Versatile effects of sildenafil: recent pharmacological applications. Pharmacol Rep 59: $150-163$

Uthayathas S, Parameshwaran K, Karuppagounder SS, Ahuja M, Dhanasekaran M, Suppiramaniam V (2013) Selective inhibition of phosphodiesterase 5 enhances glutamatergic synaptic plasticity and memory in mice. Synapse 67:741-747 